Research Article

\title{
Study on Properties of Drainage SBS Modified Asphalt Mixture with Fiber
}

\author{
Zhenxia Li, ${ }^{1,2,3}$ Tengteng Guo, ${ }^{1,2,3}$ Yuanzhao Chen $\mathbb{D}^{1},{ }^{1,2,3}$ Menghan Zhang, ${ }^{1,2,3}$ \\ Qingyu Xu $\bullet{ }^{1}{ }^{1}$ Jing Wang, ${ }^{1}$ and Lihui Jin ${ }^{1}$ \\ ${ }^{1}$ School of Civil Engineering and Communication, North China University of Water Resources and Electric Power, \\ Zhengzhou 450045, Henan, China \\ ${ }^{2}$ Henan Province Engineering Technology Research Center of Environment Friendly and High-Performance Pavement Materials, \\ Zhengzhou 450045, Henan, China \\ ${ }^{3}$ Zhengzhou City Key Laboratory of Environmentally Friendly High Performance Road and Bridge Materials, Zhengzhou 450045, \\ Henan, China
}

Correspondence should be addressed to Yuanzhao Chen; cyz740513@ncwu.edu.cn

Received 18 September 2021; Revised 19 November 2021; Accepted 20 November 2021; Published 13 December 2021

Academic Editor: Aboelkasim Diab

Copyright (c) 2021 Zhenxia Li et al. This is an open access article distributed under the Creative Commons Attribution License, which permits unrestricted use, distribution, and reproduction in any medium, provided the original work is properly cited.

In order to improve the road performance of drainage SBS modified asphalt mixture, basalt fiber was added to prepare drainage styrene-butadiene-styrene (SBS) modified asphalt mixture. The viscosity-toughness, toughness, and $60^{\circ} \mathrm{C}$ dynamic viscosity of SBS modified asphalt were tested. The modification effect was evaluated from the perspective of high and low temperature rheological properties by dynamic shear rheometer (DSR) and bending beam rheometer (BBR) tests. The high temperature stability, water stability, low temperature crack resistance, and drainage of basalt fiber SBS drainage asphalt mixture were evaluated and compared with nonfiber SBS drainage asphalt mixture and TPS drainage asphalt mixture. The morphology characteristics of asphalt mixture and the distribution of basalt fiber in the mixture were analyzed from a micro perspective. The results showed the following: the overall performance of basalt fiber is better than that of lignin fiber. SBS modifier content in $7 \%$ can meet the requirements of drainage asphalt pavement on asphalt binder. The optimum asphalt content of SBS modified asphalt mixture with basalt fiber content of $0,0.15,0.25$, and $0.35 \%$ is $4.9,5.05,5.15$, and $5.2 \%$. The fiber is irregularly distributed in the mixture to form a threedimensional network structure, which has a series skeleton function. It plays a tensile role in the initial cracking of asphalt mixture and prevents further expansion of cracks.

\section{Introduction}

With the proposal of 'sponge city' construction in China, drainage asphalt pavement has attracted more and more attention [1-3]. The drainage asphalt pavement surface layer adopts large void open graded asphalt mixture, and the middle and lower layers adopt dense graded asphalt mixture. It has good noise reduction, drainage, and antiskid performance, which can effectively improve the safety of travel in rainy days and reduce noise pollution to a certain extent $[4,5]$. Due to the small content of fine aggregate and mineral powder in the drainage asphalt pavement mixture, there are a large number of communicating interstices, air and rainwater are easy to penetrate into the internal structure, and they are prone to aging and reduce the service life; drainage asphalt mixture is an open-graded skeleton void structure with more coarse aggregate and less adhesive force, so the asphalt binder used in drainage asphalt pavement should have strong adhesion, antistripping, and water resistance to aggregate [6-13].

In order to strengthen the high and low temperature performance, skid resistance, and water stability of drainage pavement, many related studies have been conducted in China and abroad. In the 1960s, Germany first proposed the "large void asphalt pavement," namely, petroleum asphalt (spraying anionic emulsified asphalt) pavement, which was developed and applied to airport runways. The purpose is to enhance the skid resistance of runways and reduce and avoid 
the water drift generated by aircraft during the taxiing in rainy days [14]. In the 1990s, the paving test of porous asphalt pavement was carried out in Britain. The asphalt mixture used in the test section is rubber asphalt or No. 100 matrix asphalt, and fiber and $2 \%$ lime are added. It is proved that the pavement has the effect of reducing noise and rainwater film [15]. In 1999, fiber was introduced into China for the first time, and some highway projects began to use fiber as additive to improve the road performance of asphalt mixture. Through exploring the mechanism of basalt fiber in asphalt mixture $[16,17]$, it is found that basalt fiber has the best high temperature stability and shear strength among several fibers, which can significantly improve the rutting resistance factor and water stability of asphalt mortar [18-22]. Toughened polystyrene (TPS) is a high viscosity asphalt additive, which can significantly improve the high and low temperature performance of asphalt and improve the fatigue performance of asphalt pavement. However, due to the high price of TPS high viscosity asphalt modifier, it is difficult to promote it $[23,24]$. Later, SBS modifier was widely used in China. SBS is a kind of thermoplastic elastomer, which has the elasticity of rubber at room temperature and can melt and flow at high temperature. The incorporation of SBS modifier into asphalt mixture can greatly improve the rutting resistance, and the high temperature stability is also better, and the water stability of drainage asphalt mixture is effectively improved [25-29].

Basalt fiber can improve the dispersion of mineral powder, has toughening and reinforcing effect, and can improve pavement performance and prolong service life; SBS modifier has the advantages of high softening point, high viscosity, large elongation, and strong antistripping property. Adding SBS modifier into asphalt mixture can make it have good high temperature stability and durability. Therefore, both of them are used for drainage asphalt mixture to further enhance the high and low temperature stability and water damage resistance of drainage asphalt pavement. To this end, this paper intends to prepare the drainage SBS modified asphalt mixture with basalt fiber and puts forward the preparation method of high-speed shear SBS modified asphalt. The rheological properties of modified asphalt are analyzed by DSR test and BBR test. The high temperature stability, low temperature crack resistance, water stability, and drainage performance are comprehensively studied through rutting test, immersion Marshall test, freeze-thaw splitting test, and low temperature bending test. The mechanism of basalt fiber reinforced asphalt mixture on road performance is further studied from the micro level by scanning electron microscopy, so as to promote the development of drainage asphalt pavement in China.

\section{Raw Material}

2.1. Asphalt. In this test, 70\# A grade asphalt is selected, and its basic performance is tested according to the requirements of Test procedures for asphalt and asphalt mixture in highway engineering JTGE20-2011. The test results are shown in Table 1.
2.2. Coarse Aggregate. The selection of coarse aggregate should meet the requirements of dry and clean, small crushing value, and less needle flake content. According to the specification Highway engineering aggregate test procedures JTG E42-2005 requirements for coarse aggregate test, the test results of each specification are shown in Table 2.

2.3. Fine Aggregate. According to the specification Highway engineering aggregate test procedures JTG E42-2005 requirements for fine aggregate test, the test results of each specification are shown in Table 3.

2.4. Mineral Fines. The technical indicators of ore powder are shown in Table 4.

2.5. Fiber. The drainage asphalt mixture has large void ratio and low aggregate specific surface area, which may lead to segregation of mixture during paving and rolling. Therefore, the pavement performance of the mixture can be improved by adding fiber to increase the thickness of asphalt film and the grip strength between asphalt and mineral. The nominal length of basalt fiber and wood fiber is $6 \mathrm{~mm}$, and the diameter of single fiber is $16 \mu \mathrm{m}$, and the technical indexes are shown in Table 5.

\subsection{Modifier}

2.6.1. The SBS Modifier. SBS modifier is provided by Ningbo Yinzhou Pott Polymer New Materials limited company, is a thermoplastic rubber material, styrene butadiene ethylene block, and has a linear structure, as shown in Figure 1.

2.6.2. The TPS Modifier. TPS modifier is provided by Shanghai Qunkang Company; the composition is mainly thermoplastic rubber, adhesive resin, as shown in Figure 2.

\section{Test Method}

3.1. Preparation Method of Modified Asphalt. SBS modified asphalt with 7\% SBS modifier and TPS modified asphalt with $12 \%$ TPS modifier were prepared by high-speed shearing method. The specific preparation process of modified asphalt is as follows:

3.1.1. Title of Raw Materials. According to the amount and blending ratio of modified asphalt required in the test, the amount of matrix asphalt and modifier was determined. The modifier is slowly and evenly added to the matrix asphalt heated to $160^{\circ} \mathrm{C}$.

3.1.2. Preswelling. The research shows that the polymer is uniformly distributed in the base asphalt, and the improvement effect of asphalt performance will be more significant when the volume is expanded to 10 times the original volume, and then the high-speed shear is carried out. That is, after the modifier is added to asphalt, the 
TABLE 1: Technical indicators of 70 matrix asphalt.

\begin{tabular}{|c|c|c|c|c|}
\hline \multicolumn{2}{|l|}{ Test metric } & Test result & Specification requirement & Test method \\
\hline \multicolumn{2}{|c|}{ Needle penetration $\left(25^{\circ} \mathrm{C}, 100 \mathrm{~g}, 5 \mathrm{~s}\right)(0.1 \mathrm{~mm})$} & 68.2 & $60 \sim 80$ & T0604 \\
\hline \multicolumn{2}{|c|}{ Softening point (ball and ring method) $\left({ }^{\circ} \mathrm{C}\right)$} & 57.2 & $\geq 46.0$ & T0606 \\
\hline \multicolumn{2}{|c|}{ Ductility $\left(5 \mathrm{~cm} / \mathrm{min}, 15^{\circ} \mathrm{C}\right)(\mathrm{cm})$} & 106.3 & $\geq 100$ & T0605 \\
\hline \multicolumn{2}{|l|}{ Flash point $\left({ }^{\circ} \mathrm{C}\right)$} & 268 & $\geq 260$ & T0611 \\
\hline \multicolumn{2}{|c|}{ Density $\left(\mathrm{g} \cdot \mathrm{cm}^{-3}\right)$} & 1.025 & Actual measurement & T0603 \\
\hline \multicolumn{2}{|l|}{ Solubility (\%) } & 99.7 & $\geq 99.5$ & T0607 \\
\hline \multirow{3}{*}{ After RTFOT } & Mass variation (\%) & -0.1 & $-0.8 \sim+0.8$ & T0610 \\
\hline & Penetration ratio (\%) & 72.1 & $\geq 61$ & T0604 \\
\hline & Ductility $\left(5 \mathrm{~cm} \cdot \mathrm{min}^{-1}, 15^{\circ} \mathrm{C}\right)(\mathrm{cm})$ & 7 & $\geq 6$ & T0605 \\
\hline
\end{tabular}

TABle 2: Main technical index of coarse aggregate.

\begin{tabular}{|c|c|c|c|c|}
\hline Pilot projec & & Test result & Technical standard & Test method \\
\hline \multirow{4}{*}{ Crushing value of stone (\%) } & $13.2 \mathrm{~mm} \sim 16 \mathrm{~mm}$ & 15.8 & \multirow{4}{*}{$\leq 26$} & \multirow{4}{*}{ T0316 } \\
\hline & $9.5 \mathrm{~mm} \sim 13.2 \mathrm{~mm}$ & 16.7 & & \\
\hline & $4.75 \mathrm{~mm} \sim 9.5 \mathrm{~mm}$ & 18.9 & & \\
\hline & $2.36 \mathrm{~mm} \sim 4.75 \mathrm{~mm}$ & 22.5 & & \\
\hline \multirow{4}{*}{ Los Angeles wear value (\%) } & $13.2 \mathrm{~mm} \sim 16 \mathrm{~mm}$ & 14.7 & \multirow{4}{*}{$\leq 28$} & \multirow{4}{*}{ T0317 } \\
\hline & $9.5 \mathrm{~mm} \sim 13.2 \mathrm{~mm}$ & 15.1 & & \\
\hline & $4.75 \mathrm{~mm} \sim 9.5 \mathrm{~mm}$ & 18.6 & & \\
\hline & $2.36 \mathrm{~mm} \sim 4.75 \mathrm{~mm}$ & 16.5 & & \\
\hline \multirow{4}{*}{ Apparent specific gravity } & $13.2 \mathrm{~mm} \sim 16 \mathrm{~mm}$ & 2.81 & \multirow{4}{*}{$\geq 2.60$} & \multirow{4}{*}{ T0304 } \\
\hline & $9.5 \mathrm{~mm} \sim 13.2 \mathrm{~mm}$ & 2.78 & & \\
\hline & $4.75 \mathrm{~mm} \sim 9.5 \mathrm{~mm}$ & 2.75 & & \\
\hline & $2.36 \mathrm{~mm} \sim 4.75 \mathrm{~mm}$ & 2.69 & & \\
\hline \multirow{4}{*}{ Water absorption (\%) } & $13.2 \mathrm{~mm} \sim 16 \mathrm{~mm}$ & 1.2 & \multirow{4}{*}{$\leq 2.0$} & \multirow{4}{*}{ T0304 } \\
\hline & $9.5 \mathrm{~mm} \sim 13.2 \mathrm{~mm}$ & 1.4 & & \\
\hline & $4.75 \mathrm{~mm} \sim 9.5 \mathrm{~mm}$ & 0.8 & & \\
\hline & $2.36 \mathrm{~mm} \sim 4.75 \mathrm{~mm}$ & 1.1 & & \\
\hline \multirow{4}{*}{$\begin{array}{l}\text { Water washing method }<0.075 \mathrm{~mm} \\
\text { Particles content }(\%)\end{array}$} & $13.2 \mathrm{~mm} \sim 16 \mathrm{~mm}$ & 0.5 & \multirow{4}{*}{$\leq 1$} & \multirow{4}{*}{ T0310 } \\
\hline & $9.5 \mathrm{~mm} \sim 13.2 \mathrm{~mm}$ & 0.8 & & \\
\hline & $4.75 \mathrm{~mm} \sim 9.5 \mathrm{~mm}$ & 0.7 & & \\
\hline & $2.36 \mathrm{~mm} \sim 4.75 \mathrm{~mm}$ & 0.8 & & \\
\hline \multirow{4}{*}{ Soft stone content $(\%)$} & $13.2 \mathrm{~mm} \sim 16 \mathrm{~mm}$ & 2.2 & \multirow{4}{*}{$\leq 3$} & \multirow{4}{*}{ T0320 } \\
\hline & $9.5 \mathrm{~mm} \sim 13.2 \mathrm{~mm}$ & 1.7 & & \\
\hline & $4.75 \mathrm{~mm} \sim 9.5 \mathrm{~mm}$ & 2.5 & & \\
\hline & $2.36 \mathrm{~mm} \sim 4.75 \mathrm{~mm}$ & 1.9 & & \\
\hline
\end{tabular}

TABLE 3: Main technical index of fine aggregate.

\begin{tabular}{|c|c|c|c|c|}
\hline \multicolumn{2}{|c|}{ Pilot project } & Test result & Technical standard & Test method \\
\hline Apparent specific gravity & $\begin{array}{c}1.18 \mathrm{~mm} \sim 2.36 \mathrm{~mm} \\
0.6 \mathrm{~mm} \sim 1.18 \mathrm{~mm}\end{array}$ & $\begin{array}{l}2.81 \\
2.80 \\
\end{array}$ & $\geq 2.50$ & T0328 \\
\hline Sand equivalent (\%) & $\begin{array}{c}1.18 \mathrm{~mm} \sim 2.36 \mathrm{~mm} \\
0.6 \mathrm{~mm} \sim 1.18 \mathrm{~mm}\end{array}$ & $\begin{array}{l}72 \\
68 \\
\end{array}$ & $\geq 60$ & T0344 \\
\hline Angularity (s) & $\begin{array}{c}1.18 \mathrm{~mm} \sim 2.36 \mathrm{~mm} \\
0.6 \mathrm{~mm} \sim 1.18 \mathrm{~mm}\end{array}$ & $\begin{array}{l}31 \\
32\end{array}$ & $\geq 30$ & T0345 \\
\hline
\end{tabular}

polymer is preswelling, which makes it easier to shear and grind. Therefore, this experiment first sheared at a low speed of $600 \mathrm{r} / \mathrm{min}$ for $15 \mathrm{~min}$ to ensure the full swelling of the modifier.

3.1.3. High-Speed Shearing. After the modifier is fully swelling, the shear rate is increased to $4500 \mathrm{r} / \mathrm{min}$ under the condition of high-speed shear $40 \mathrm{~min}$, so that the different components of asphalt are redistributed to prepare the required modified asphalt.

\subsection{Determination Method of Optimum Dosage Combination}

3.2.1. Determination of Mineral Grading. According to the recommended grading range of OGFC-13 for drainage asphalt mixture in the specification, the pass rate of $2.36 \mathrm{~mm}$ 
TABLe 4: Main technical indexes of mineral powder.

\begin{tabular}{|c|c|c|c|c|}
\hline \multicolumn{2}{|c|}{ Pilot project } & Test result & Technical standard & Test method \\
\hline Apparent density $\left(\mathrm{t} \cdot \mathrm{m}^{-3}\right)$ & $\begin{array}{c}0.3 \mathrm{~mm} \sim 0.6 \mathrm{~mm} \\
0.15 \mathrm{~mm} \sim 0.3 \mathrm{~mm} \\
0.075 \mathrm{~mm} \sim 0.15 \mathrm{~mm} \\
<0.075 \mathrm{~mm}\end{array}$ & $\begin{array}{l}2.81 \\
2.83 \\
2.84 \\
2.93\end{array}$ & $\geq 2.50$ & T0352 \\
\hline Moisture content (\%) & $\begin{array}{c}0.3 \mathrm{~mm} \sim 0.6 \mathrm{~mm} \\
0.15 \mathrm{~mm} \sim 0.3 \mathrm{~mm} \\
0.075 \mathrm{~mm} \sim 0.15 \mathrm{~mm} \\
<0.075 \mathrm{~mm}\end{array}$ & $\begin{array}{l}0.1 \\
0.1 \\
0.1 \\
0.1\end{array}$ & $\leq 1$ & T0103 \\
\hline Appearance & $\begin{array}{c}0.3 \mathrm{~mm} \sim 0.6 \mathrm{~mm} \\
0.15 \mathrm{~mm} \sim 0.3 \mathrm{~mm} \\
0.075 \mathrm{~mm} \sim 0.15 \mathrm{~mm} \\
<0.075 \mathrm{~mm}\end{array}$ & $\begin{array}{l}\text { without } \\
\text { without } \\
\text { without } \\
\text { without }\end{array}$ & No agglomerates & T0351 \\
\hline Hydrophilic coefficient & $\begin{array}{c}0.3 \mathrm{~mm} \sim 0.6 \mathrm{~mm} \\
0.15 \mathrm{~mm} \sim 0.3 \mathrm{~mm} \\
0.075 \mathrm{~mm} \sim 0.15 \mathrm{~mm} \\
<0.075 \mathrm{~m}\end{array}$ & $\begin{array}{l}0.1 \\
0.1 \\
0.1 \\
0.1\end{array}$ & $<1$ & T0353 \\
\hline Plasticity index (\%) & $\begin{array}{c}0.3 \mathrm{~mm} \sim 0.6 \mathrm{~mm} \\
0.15 \mathrm{~mm} \sim 0.3 \mathrm{~mm} \\
0.075 \mathrm{~mm} \sim 10.15 \mathrm{~mm} \\
<0.075 \mathrm{~mm}\end{array}$ & $\begin{array}{l}2.2 \\
2.1 \\
2.2 \\
2.2\end{array}$ & $<4$ & T0354 \\
\hline
\end{tabular}

TABle 5: Technical specifications for different types of fibers.

\begin{tabular}{lccccc}
\hline Fiber class & Breaking strength (MPa) & Elastic modulus $(\mathrm{GPa})$ & Oil absorption ratio (\%) & Water absorption (\%) & Mass loss (\%) \\
\hline Basalt fiber & 3000 & 110 & 4.2 & 0.6 & 1.1 \\
Lignin fiber & $<300$ & 33 & 8.8 & 4.7 & 5.7 \\
\hline
\end{tabular}

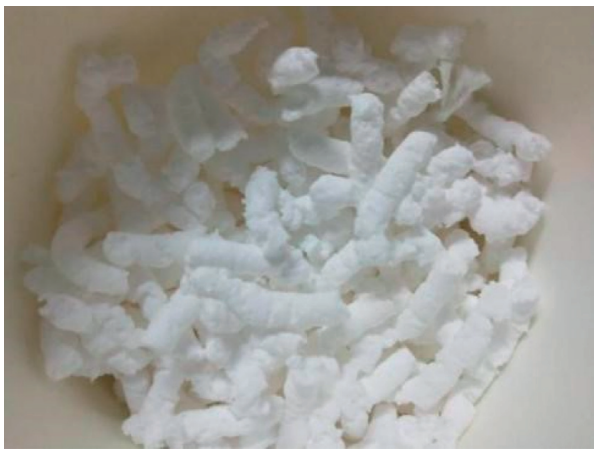

Figure 1: The SBS modifier.

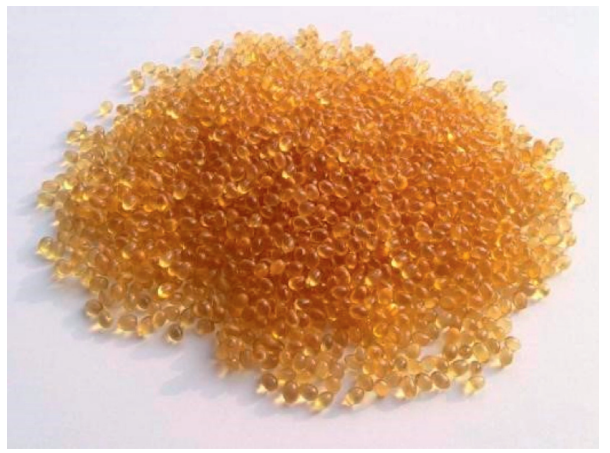

Figure 2: The TPS modifier. sieve hole is adjusted, and three initial grading schemes are selected based on the grading median, as shown in Table 6 .

The initial asphalt contents of the three groups of gradations are obtained by theoretical calculation, which are $4.9 \%, 4.7 \%$, and $4.3 \%$, respectively. Then, the Marshall specimens of SBS drainage asphalt mixture and TPS drainage asphalt mixture are formed by the target gradation and the corresponding initial asphalt content, and the void ratio of the specimens is measured. Studies have shown that when the target porosity is about $20 \%$, the drainage asphalt pavement can not only ensure excellent drainage performance, but also ensure good structural performance. Therefore, $20 \%$ was selected as the target porosity for this topic. The test results are shown in Table 7.
The analysis in Table 7 shows that the void ratio of gradation 1 is small, and the void ratio of gradation 3 is large. The void ratio of SBS drainage asphalt mixture and TPS drainage asphalt mixture at gradation 2 is closer to the target void ratio of $20 \%$. So, choose gradation 2 as target gradation.

\subsubsection{Determination of Optimum Asphalt Content}

(1) Drain-Down Test. Leakage test is using asphalt mixture test procedures T0732 beaker method for testing; the specific steps are as follows: $1 \mathrm{~kg}$ of asphalt mixture will be mixed into the mass of $800 \mathrm{ml}$ dry clean beaker, called the total mass of $m_{1}$. The glass cover was added to the beaker and placed in an oven at $170^{\circ} \mathrm{C}$. After $1 \mathrm{~h}$, the beaker was removed, and the 
TABLE 6: Mineral aggregate gradation of OGFC-13 asphalt mixture.

\begin{tabular}{|c|c|c|c|c|c|c|c|c|c|c|}
\hline \multirow{2}{*}{ Grading type } & \multicolumn{10}{|c|}{ Through the following sieve hole $(\mathrm{mm})$ mass percentage $(\%)$} \\
\hline & 16 & 13.2 & 9.5 & 4.75 & 2.36 & 1.18 & 0.6 & 0.3 & 0.15 & 0.075 \\
\hline Upper limit & 100 & 100 & 80 & 30 & 22 & 18 & 15 & 12 & 8 & 6 \\
\hline Lower limit & 100 & 90 & 60 & 12 & 10 & 6 & 4 & 3 & 3 & 2 \\
\hline Median & 100 & 95 & 70 & 21 & 16 & 12 & 9.5 & 7.5 & 5.5 & 4 \\
\hline Gradation 1 & 100 & 95.2 & 74.1 & 26.9 & 18.2 & 12.8 & 9.8 & 6.7 & 5.1 & 4.1 \\
\hline Gradation 2 & 100 & 94.6 & 70.8 & 23.3 & 15.6 & 11.2 & 8.7 & 6.2 & 4.9 & 4.1 \\
\hline Gradation 3 & 100 & 93.9 & 67.4 & 20.2 & 13.2 & 9.4 & 7.3 & 5.2 & 4 & 3.3 \\
\hline
\end{tabular}

TABLe 7: Mineral aggregate gradation of OGFC-13 asphalt mixture.

\begin{tabular}{lccc}
\hline Mixture type & Grading scheme & Asphalt-stone ratio (\%) & Percentage of void (\%) \\
\hline \multirow{3}{*}{ SBS bituminous mixture } & Gradation 1 & 4.9 & 17.7 \\
& Gradation 2 & 4.7 & 19.4 \\
\hline \multirow{3}{*}{ TPS bituminous mixture } & Gradation 3 & 4.3 & 21.7 \\
& Gradation 1 & 4.9 & 17.6 \\
& Gradation 2 & 4.7 & 19.2 \\
\hline
\end{tabular}

mixture was poured onto the glass plate. The total mass of the beaker and the adhesive was recorded as $m_{2}$. The leakage loss is calculated according to Formula (1). The specification requires that, for the drainage asphalt mixture, the leakage loss in the leakage test should be $\leq 0.8 \%$. TPS drainage asphalt mixture and SBS drainage asphalt mixture with basalt fiber content of $0 \%, 0.15 \%, 0.25 \%$, and $0.35 \%$ were made with $0.5 \%$ oil-aggregate ratio in the range of $4 \% \sim 6 \%$ oilaggregate ratio. The inflection point of the curve in the leakage loss-oil-aggregate ratio diagram was taken as the maximum asphalt content.

$$
\Delta m=\frac{m_{2}-m_{0}}{m_{1}-m_{0}} \times 100 .
$$

In the formula: $\Delta m$--loss rate of leakage, \%; $m_{0}$ - cup quality, g; $m_{1}-$ - total quality of beaker and asphalt mixture, g.

(2) Leakage Test Results. The results of leakage test are shown in Table 8 and Figure 3. Taking the inflection point of the curve in the leakage loss-oil ratio diagram as the maximum asphalt content, the maximum asphalt content of SBS modified asphalt mixture with basalt fiber content of $0 \%$, $0.15 \%, 0.25 \%$, and $0.35 \%$ is $5.0 \%, 5.1 \%, 5.2 \%$, and $5.25 \%$, respectively. The maximum asphalt content of TPS modified asphalt mixture is $4.9 \%$. With the increase of fiber content, asphalt content increases accordingly. The reason is that the huge specific surface area of fiber can become the interface of asphalt infiltration, so as to adsorb asphalt, increase the amount of asphalt, and increase the thickness of asphalt structural film, so the higher the fiber content, the higher the maximum asphalt content of asphalt mixture.

(3) CANTABRO Test. The specific steps of the Scattering loss test are as follows: Marshall specimens were placed in a constant temperature water bath at $20^{\circ} \mathrm{C}$ and $0.5^{\circ} \mathrm{C}$ for $20 \mathrm{~h}$. The specimen was taken out and weighed as $m_{0}$. Put it into the Los Angeles wear testing machine, without steel ball, set the speed of $30 \sim 33 \mathrm{r} / \mathrm{min}$, and the revolution is $300 \mathrm{r}$. Then, the broken specimen was taken out, and the maximum test block in the residual test block was selected for weighing, denoted as $m_{1}$. Calculate the dispersion loss rate, as shown in formula (2). Within the range of $4 \%-6 \%$ of the oil-stone ratio, TPS modified asphalt Marshall specimens and SBS modified asphalt Marshall specimens with 0\%, 0.15\%, 0.25\%, and $0.35 \%$ basalt fiber content were prepared with $0.5 \%$ of the oil-stone ratio to conduct the dispersion test. The minimum asphalt content takes the inflection point of the curve in the dispersion loss-oil ratio diagram.

$$
\Delta S=\frac{m_{0}-m_{1}}{m_{0}} \times 100 .
$$

In the formula: $\Delta S$ - - scattering loss, $\% ; m_{0}$ - - quality of specimen before test, $\mathrm{g} ; m_{1}-$-maximum residual mass after test, g.

(4) Results of Scattering Loss Test. The results of scattering loss test are shown in Table 9 and Figure 4, The maximum asphalt content of SBS modified asphalt mixture with $0 \%$, $0.15 \%, 0.25 \%$, and $0.35 \%$ basalt fiber is $5.0 \%, 5.1 \%, 5.2 \%$, and $5.25 \%$, respectively; The minimum asphalt content is $4.8 \%$, $5.0 \%, 5.1 \%$, and $5.15 \%$, respectively. The maximum asphalt content of TPS drainage asphalt mixture is $4.9 \%$, and the minimum asphalt content is $4.7 \%$. With the increase of fiber content, the amount of asphalt also increases accordingly, because the huge specific surface area of fiber can become the interface of asphalt infiltration, so as to adsorb asphalt, increase the amount of asphalt, and increase the thickness of asphalt structural film. The leakage loss rate and dispersion loss rate of SBS drainage asphalt mixture with basalt fiber are significantly lower than those of SBS drainage asphalt mixture without basalt fiber. With the increase of fiber content, the leakage loss rate and dispersion loss rate show a trend of first decreasing and then increasing. The reason is that after the fiber is mixed with the asphalt mixture, it produces physical infiltration or even chemical bond with 
TABLE 8: The leakage test results of different drainage asphalt mixtures are summarized.

\begin{tabular}{|c|c|c|c|c|c|}
\hline \multirow{2}{*}{ Asphalt-stone ratio (\%) } & \multicolumn{5}{|c|}{$\Delta m(\%)$} \\
\hline & Fiber-free SBS & $0.15 \%$ fiber SBS & $0.25 \%$ fiber SBS & $0.35 \%$ fiber SBS & TPS \\
\hline 4.0 & 0.05 & 0.031 & 0.025 & 0.029 & 0.071 \\
\hline 4.5 & 0.16 & 0.052 & 0.045 & 0.049 & 0.172 \\
\hline 5.0 & 0.54 & 0.081 & 0.071 & 0.075 & 0.388 \\
\hline 5.5 & 1.46 & 0.127 & 0.114 & 0.118 & 1.014 \\
\hline 6.0 & 2.78 & 0.031 & 0.175 & 0.182 & 1.672 \\
\hline
\end{tabular}

the surface active substances in the asphalt. The asphalt is wrapped on the surface of the fiber to inhibit its free flow and reduce the leakage loss and dispersion loss; however, when the fiber content exceeds a certain amount, it is difficult for the fiber to be uniformly dispersed, and it will be intertwined or even agglomerated. The asphalt mixture in the agglomerated part will gather more free asphalt, and the leakage loss and dispersion loss will increase instead.

3.2.3. Determination of Fiber Content. The test results are shown in Table 10 and Figures 5-7.

The analysis of the test results shows the following:

With the increase of fiber content, the porosity and mineral gap rate decrease accordingly, and the asphalt saturation increases. Because the increase of fiber content will increase the asphalt content and occupy more voids, the porosity and mineral gap rate decrease accordingly, and the asphalt saturation increases. However, the three changes are not significant, because the drainage asphalt mixture is the skeleton void structure, and the gradation type is the decisive factor affecting the void ratio. The fiber content and asphalt content have little effect on it. It can be seen from Figure 8 that Marshall stability increases with the increase of fiber content. When the basalt fiber content is $0.25 \%$, the stability has a peak value of $7.76 \mathrm{kN}$. The reason is that the high tensile strength of basalt fiber can improve the strength of drainage asphalt mixture, thus improving the stability and the ability to resist deformation. However, when the fiber content is too high, the fiber is difficult to be evenly distributed in the mixture, entangled together, and the fiber cannot give full play to its role. When subjected to load, stress concentration may occur, resulting in local damage and Marshall stability decreases. The stability reaches the peak when the basalt fiber content is $0.25 \%$, and the leakage loss rate and dispersion loss rate are the smallest when the basalt fiber content is $0.25 \%$, indicating that the fiber can play a better role and enhance the performance of the mixture. Therefore, $0.25 \%$ basalt fiber is selected as the best dosage.

\subsection{Test Method for Rheological Properties}

3.3.1. Dynamic Shear Test. Using dynamic shear rheometer: According to the specification JTG E20-2011, T0628-2011, in the temperature range of $58^{\circ} \mathrm{C}-82^{\circ} \mathrm{C}$, the temperature of matrix asphalt, 7\% SBS modified asphalt, and 12\% TPS modified asphalt was scanned for each increase of $6^{\circ} \mathrm{C}$. The control strain mode was selected, and the loading strain was uniformly selected as $10 \%$. The loading frequency was $10 \mathrm{rad} / \mathrm{s}$, and the sample size was $25 \mathrm{~mm} \times 2 \mathrm{~mm}$. The complex shear modulus $G *$, phase angle $\delta$, rutting factor $G * / \sin \delta$ and other parameters of the matrix asphalt before and after aging and the composite modified asphalt before and after aging were tested by dynamic shear rheometer to study the high-temperature performance of the composite modified asphalt.

3.3.2. Flexural Creep Stiffness Test. Using bending beam rheometer: The BBR test of matrix asphalt, 7\% SBS modified asphalt, and $12 \%$ TPS modified asphalt at $-12^{\circ} \mathrm{C},-18^{\circ} \mathrm{C}$ and $-24^{\circ} \mathrm{C}$ was carried out to determine the bending creep stiffness modulus $S$ and creep curve slope $m$, and the low temperature crack resistance of asphalt was studied.

\subsection{Road Performance Test Method}

3.4.1. High-Temperature Stability. The YLDCX-6 automatic wheel milling machine is used. Three rut boards of fiber-free SBS drainage asphalt mixture, $0.25 \%$ basalt fiber content SBS drainage asphalt mixture, and TPS drainage asphalt mixture are formed, respectively, with the volume of $300 \mathrm{~mm} \times 300 \mathrm{~mm} \times 50 \mathrm{~mm}$. Then, the YLDCZ-8S rut tester is used, and the test is carried out at $60^{\circ} \mathrm{C}, 42 \mathrm{times} / \mathrm{min}$ and $0.7 \mathrm{MPa}$.

\subsubsection{Water Stability}

(1) Immersion Marshall Test. Eight standard Marshall specimens of three kinds of drainage asphalt mixtures were formed, respectively, and the residual stability, namely, the ratio of the stability of the specimen soaked for $48 \mathrm{~h}$ and $0.5 \mathrm{~h}$ at $60^{\circ} \mathrm{C}$, was used as the evaluation standard. The larger the value was, the stronger the ability of the mixture to resist water damage was. In this experiment, the DF stability tester was used to measure the stability, and then the residual stability was obtained.

(2) Freeze-Thaw Splitting Test. Marshall specimens of three kinds of drainage asphalt mixtures were formed in two groups, and the first group was subjected to splitting test after water bathing at $25^{\circ} \mathrm{C}$ for $2 \mathrm{~h}$. The second group was saturated for $15 \mathrm{~min}$ under the condition of $97.3 \sim 98.7 \mathrm{kPa}$ vacuum degree. The specimens were placed in a plastic bag, and $10 \mathrm{~mL}$ water was added. The specimens were placed at $-18^{\circ} \mathrm{C}$ for $16 \mathrm{~h}$ and then bathed at $60^{\circ} \mathrm{C}$ for $24 \mathrm{~h}$. Finally, the splitting test was carried out at $25^{\circ} \mathrm{C}$ for $2 \mathrm{~h}$. 


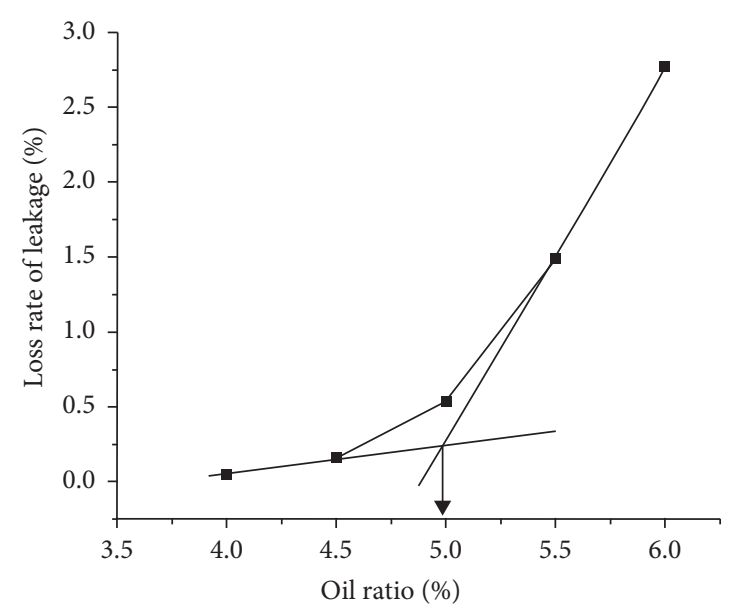

(a)

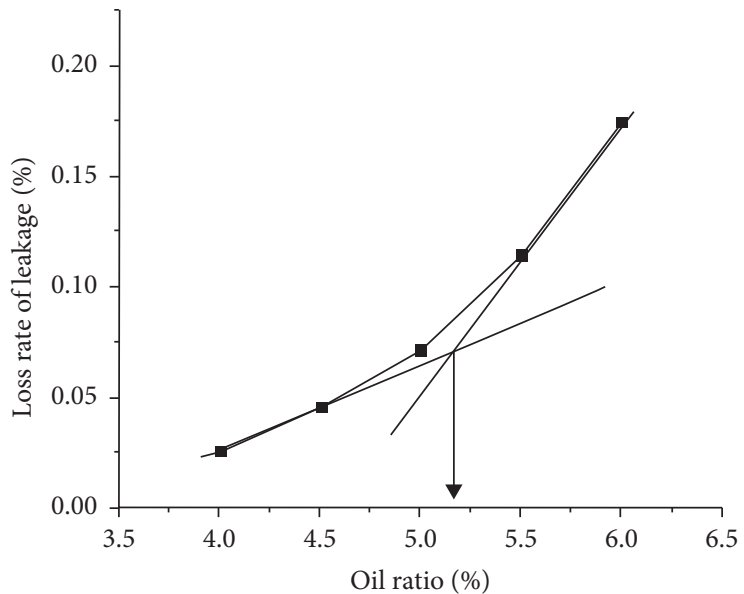

(c)

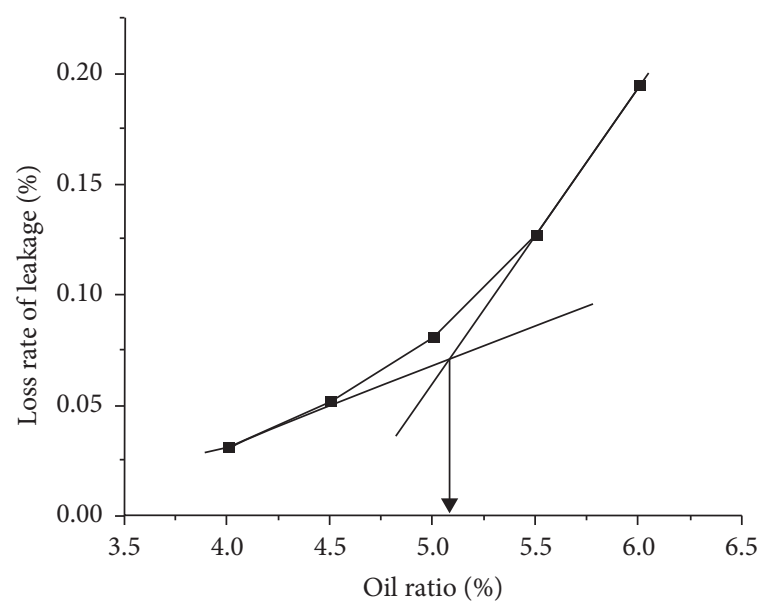

(b)

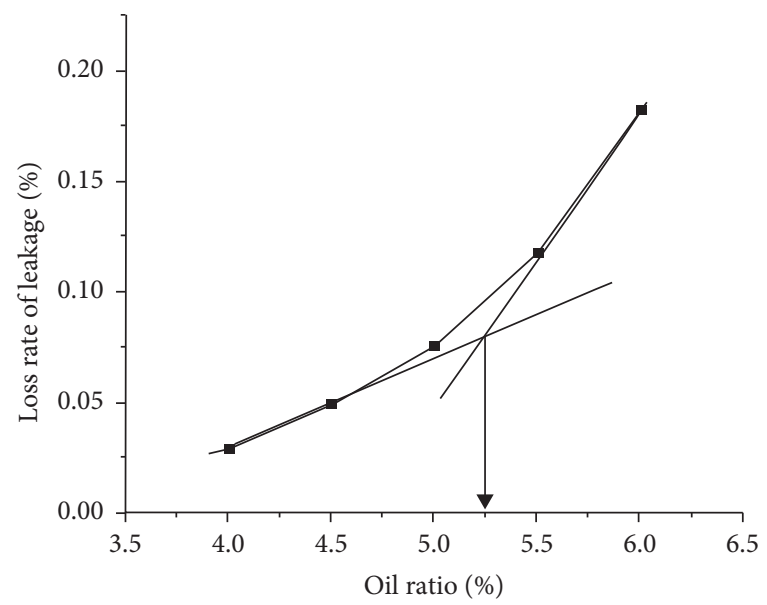

(d)

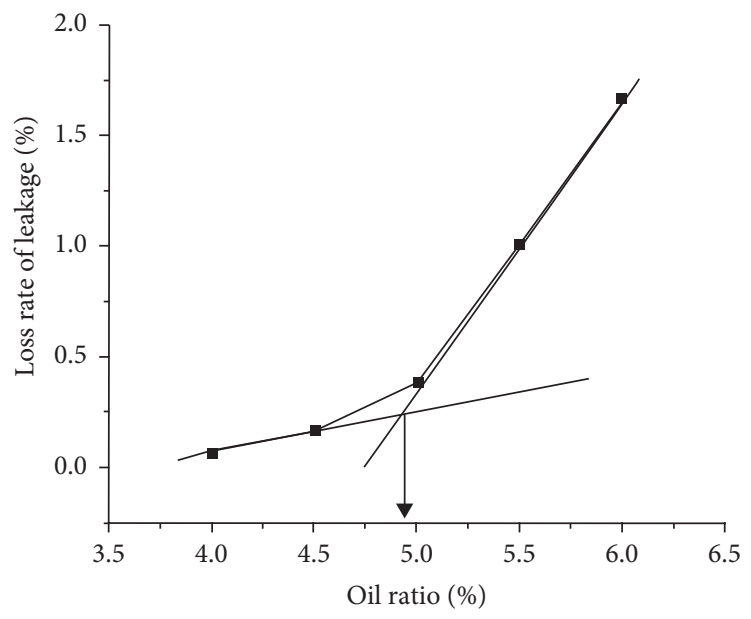

(e)

FIgURE 3: Leakage loss-whetstone ratio diagram. (a) Leakage loss-oil-aggregate ratio diagram of fiber-less SBS. (b) The leakage loss-oilaggregate ratio diagram of $0.15 \%$ SBS fiber. (c) The leakage loss-oil-aggregate ratio diagram of $0.25 \%$ SBS fiber. (d) The leakage loss-oilaggregate ratio diagram of $0.35 \%$ SBS fiber. (e) TPS leakage loss-oil-rock ratio diagram.

(3) Immersion and Scattering Test. The Marshall specimen was placed at $60^{\circ} \mathrm{C}$ for $48 \mathrm{~h}$ and then placed at room temperature for $24 \mathrm{~h}$. The mass of the specimen was weighed, and then the specimen was put into the Los
Angeles testing machine to rotate 300 revolutions at a speed of $33 \mathrm{r} / \mathrm{min}$. The mass of the specimen was taken out, and the dispersion loss was calculated and compared with the standard dispersion loss. 
TABLE 9: Comparison of test results of different drainage asphalt mixtures.

\begin{tabular}{|c|c|c|c|c|c|}
\hline \multirow{2}{*}{ Asphalt-stone ratio (\%) } & \multicolumn{5}{|c|}{$\Delta S(\%)$} \\
\hline & Fiber-free SBS & $0.15 \%$ fiber SBS & $0.25 \%$ fiber SBS & $0.35 \%$ fiber SBS & TPS \\
\hline 4.0 & 18.83 & 16.54 & 13.36 & 14.86 & 17.12 \\
\hline 4.5 & 14.32 & 12.43 & 9.67 & 11.03 & 12.63 \\
\hline 5.0 & 10.88 & 9.36 & 6.97 & 8.12 & 9.45 \\
\hline 5.5 & 7.75 & 6.51 & 4.26 & 5.25 & 6.84 \\
\hline 6.0 & 5.35 & 4.35 & 3.18 & 3.87 & 4.65 \\
\hline
\end{tabular}

3.4.3. Low Temperature Crack Resistance. The low temperature bending test of the beam was used to evaluate the low temperature crack resistance of the drainage asphalt mixture. In other words, the vertical pressure was applied in the middle of the beam until the beam was damaged. The ability of the mixture to resist deformation under lowtemperature conditions was simulated. The evaluation indexes were flexural tensile strength, maximum flexural tensile strain, and flexural stiffness modulus.

The rutting plates of SBS drainage asphalt mixture with basalt fiber, TPS drainage asphalt mixture, and nonfiber SBS drainage asphalt mixture were cut into small beams with a volume of $30 \mathrm{~mm} \times 35 \mathrm{~mm} \times 250 \mathrm{~mm}$, respectively. The asphalt mixture multifunctional dynamic test system was used to load at the midpoint under the conditions of $-10^{\circ} \mathrm{C}$ of test temperature and $50 \mathrm{~mm} \cdot \mathrm{min}^{-1}$ of loading speed, and the required data for the test were calculated.

3.5. Test Method for Drainage Performance. The basic steps of seepage test are as follows: the asphalt mixture specimen was formed by wheel milling method. The steel ring was placed in the central position of the specimen, and the lines were marked along the inner ring and the outer ring by chalk. Take off the steel ring, the two-ring clamp part with waterproof putty; '/'mm for sealing treatment. Place the pavement water seepage meter at the measuring point and press down the base of the water seepage meter to enhance the water tightness and prevent water from flowing out of the gap or other gap between the water seepage meter and the sealing material. Exhaust the air in the water meter and fill the water, open the switch, and when the water surface drops to $100 \mathrm{~mL}$, start timing. When the water surface drops to $500 \mathrm{~mL}$, stop counting and calculate the seepage coefficient.

\subsection{Microanalysis}

3.6.1. Scanning Electron Microscope Test. JSM-7500F scanning electron microscope (SEM) was used to observe the microscopic characteristics of splitting failure of basalt fiber SBS drainage asphalt mixture and fiber-less SBS drainage asphalt mixture and the distribution of basalt fiber in the mixture. The length, width, and height of the specimen are $2 \mathrm{~cm} \times 2 \mathrm{~cm} \times 1 \mathrm{~cm}$, and the automatic magnetron sputtering instrument is used to spray gold for $15 \mathrm{~s}$ at $40 \mathrm{~mA}$ current, so that the specimen has enough conductivity.

\section{Results and Discussion}

4.1. Determination of Modifier Dosage. The comparison results of main performance indexes are shown in Table 11. It can be seen from Table 11 that the decrease of penetration of the two modified asphalts indicates that the viscosity of asphalt increases and the road performance is improved. The low temperature ductility of modified asphalt has been further improved. SBS modifier exceeds the modification effect of TPS modifier, indicating that SBS modified asphalt has better low temperature crack resistance. The modified asphalt with high dynamic viscosity at $60^{\circ} \mathrm{C}$ can form thick asphalt film and has good adhesion performance, thus improving the water stability and durability of the mixture.

\subsection{Analysis of Rheological Properties}

4.2.1. Dynamic Shear Test. The test results are shown in Figures 9 and 10, and the analysis in Figures 9 and 10 shows that, with the increase of temperature, the phase angle of matrix asphalt increases, indicating that the proportion of viscoelastic components has changed, and the matrix asphalt is transformed from elasticity to viscosity. However, SBS modified asphalt showed a trend of first increase and then decrease, because with the increase of temperature, the activity of modifier increased with the increase of temperature, which increased the proportion of elastic components in modified asphalt. The phase angle of TPS modified asphalt was lower than that of SBS modified asphalt, indicating that the proportion of elastic components was large, the ability to restore deformation was stronger, and the ability to resist high temperature deformation was stronger. Peng et al. studied the performance of modified lignocellulose and SMA-13 asphalt mixture and concluded that when the yield of modified lignocellulose ranged from $0.3 \%$ to $0.5 \%$, the rutting resistance was the best [30]. In this experiment, with the increase of temperature, the complex shear modulus and rutting factor of the three asphalts show a decreasing trend, indicating that the antirutting deformation ability is reduced. Meanwhile, because the rutting factor of TPS modified asphalt is higher than that of SBS modified asphalt, TPS modified asphalt has better rutting resistance.

4.2.2. Flexural Creep Stiffness Test. The test results are shown in Figures 11 and 12; by analyzing Figures 11 and 12, it can be seen that the stiffness modulus of the three kinds of asphalt increases with the decrease of temperature, which reflects that the brittleness of asphalt increases with the 


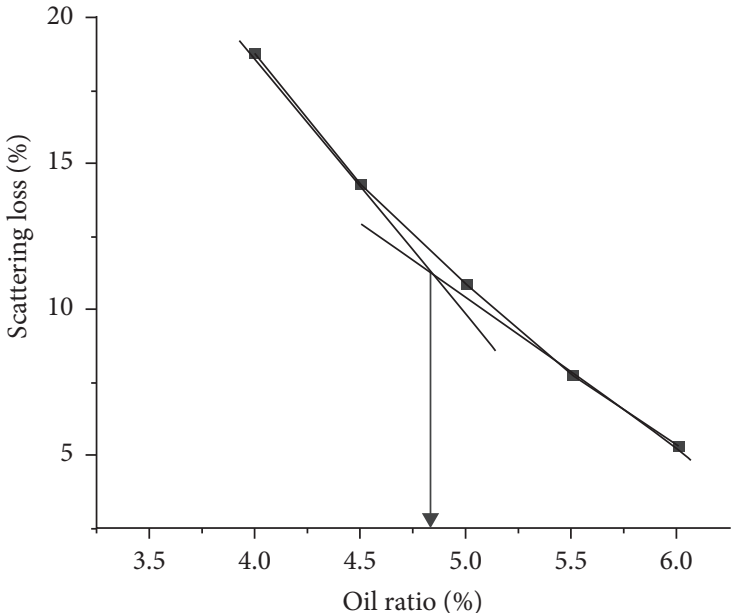

(a)

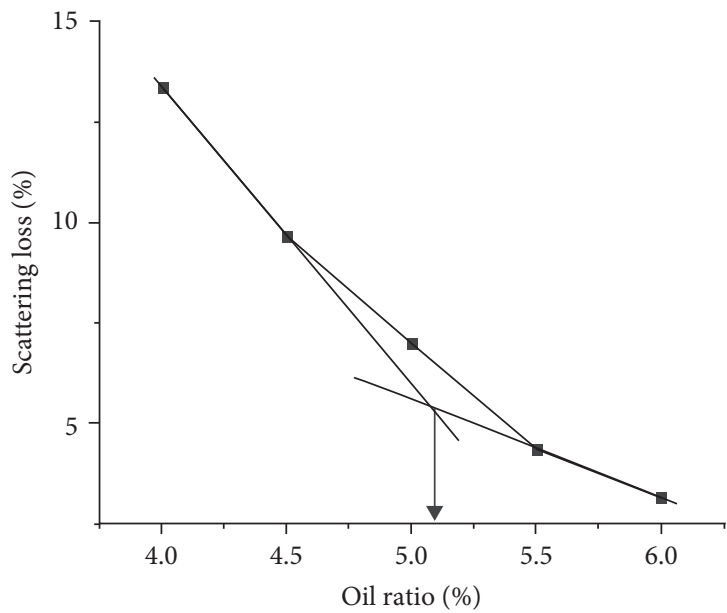

(c)

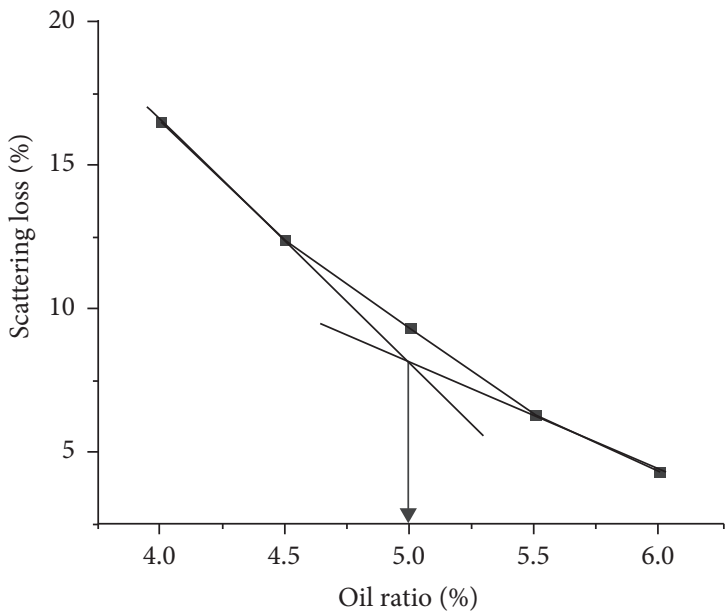

(b)

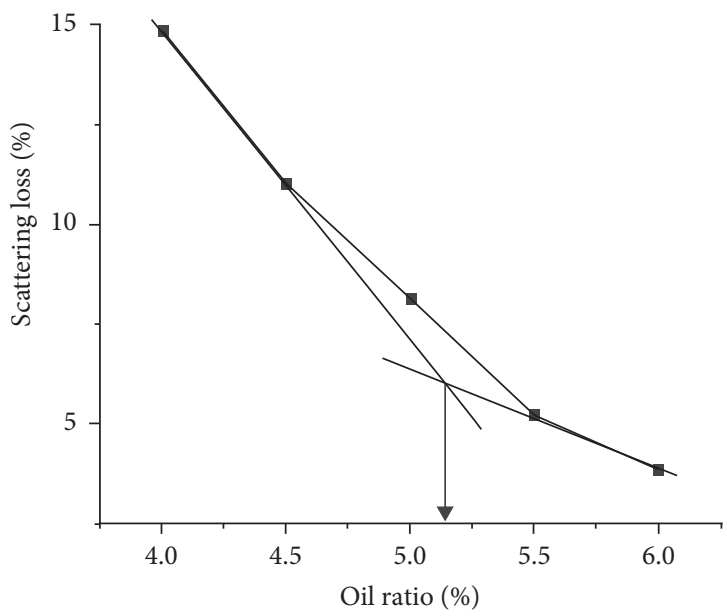

(d)

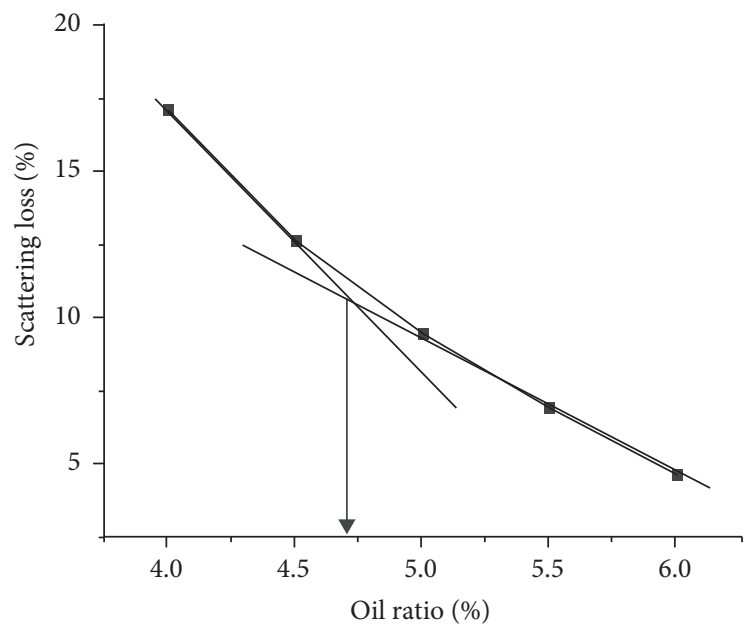

(e)

FIgURE 4: Scatter loss-whetstone ratio diagram. (a) Float loss-oil-aggregate ratio diagram of fiberless SBS. (b) Float loss-oil-petroleum ratio diagram of $0.15 \%$ fiber SBS. (c) Float loss-oil-petroleum ratio diagram of $0.25 \%$ fiber SBS. (d) Float loss-oil-petroleum ratio diagram of $0.35 \%$ fiber SBS. (e) TPS float loss-oil-petroleum ratio diagram.

decrease of temperature, and it is easy to crack at low temperature. Huang et al. in the study of basalt fiber asphalt mixture fatigue properties obtained $0.4 \%$ dosage of $9 \mathrm{~mm}$ basalt fiber asphalt mixture, and low temperature crack resistance is the best, 1.3 times for ordinary asphalt mixture [31]. The smaller the stiffness modulus, the greater the 
TABLE 10: Marshall test results of SBS asphalt mixture with different content of fiber.

\begin{tabular}{|c|c|c|c|c|c|c|}
\hline Fiber content $(\%)$ & Asphalt-stone ratio (\%) & Degree of stability $(\mathrm{kN})$ & Flow value $\left(10^{-1} \mathrm{~mm}\right)$ & VV (\%) & VMA (\%) & VFA (\%) \\
\hline 0 & 4.90 & 6.02 & 22.7 & 20.1 & 28.8 & 30.5 \\
\hline 0.15 & 5.05 & 6.85 & 20.4 & 19.9 & 28.3 & 31.1 \\
\hline 0.25 & 5.15 & 7.76 & 27.5 & 19.6 & 27.9 & 31.4 \\
\hline 0.35 & 5.20 & 6.93 & 23.2 & 19.2 & 27.6 & 31.6 \\
\hline
\end{tabular}

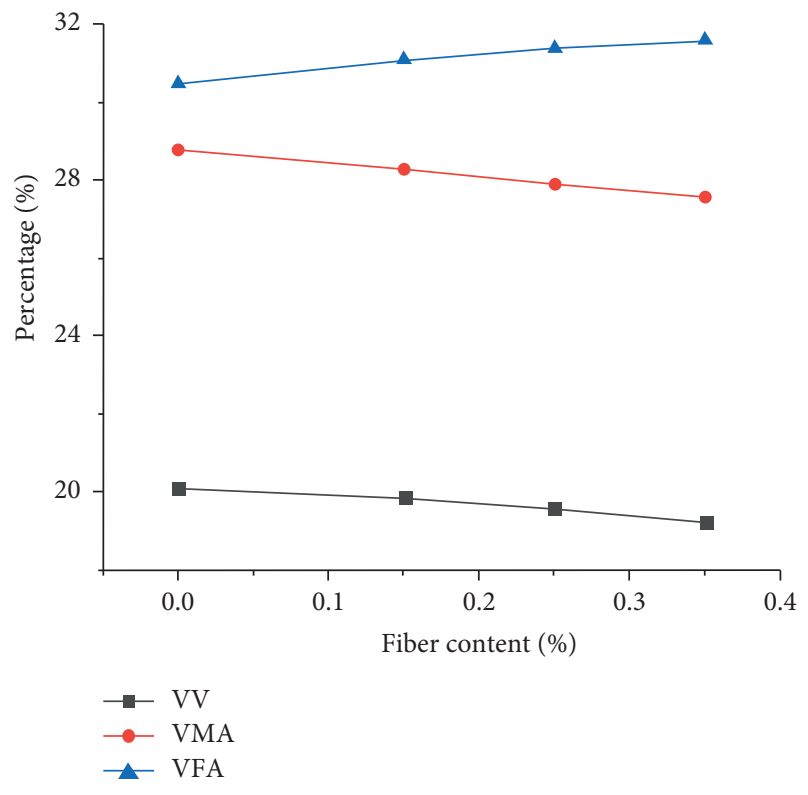

Figure 5: Basalt fiber content-asphalt mixture volume index diagram.

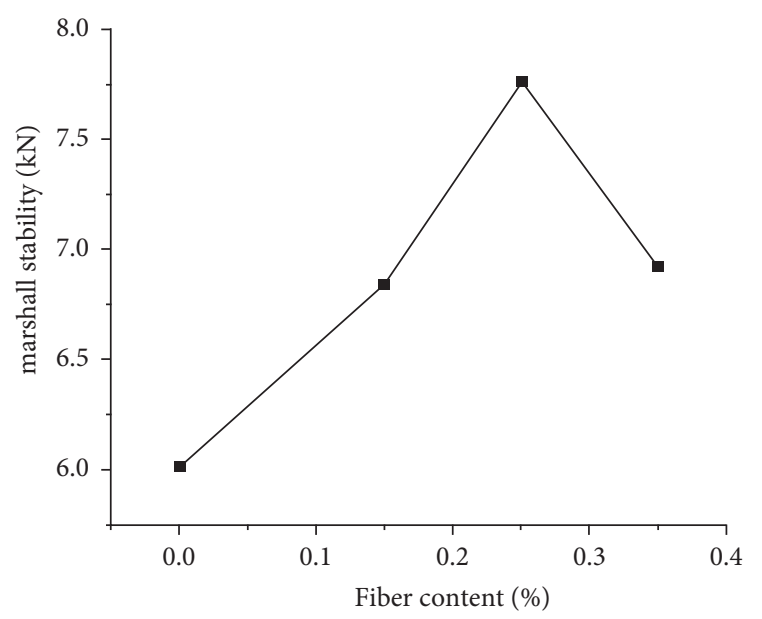

FIGURE 6: Basalt fiber content-Marshall stability relationship diagram.

energy required for material failure, and the better the crack resistance, and the SBS modified asphalt has better low temperature crack resistance. With the decrease of temperature, the creep rate of three kinds of asphalt is also reduced. The maximum creep rate of SBS modified asphalt is $m$, and the stiffness modulus $S$ changes faster with time. Under low temperature environment, the stiffness modulus $S$ value decreases rapidly, which reduces the possibility of

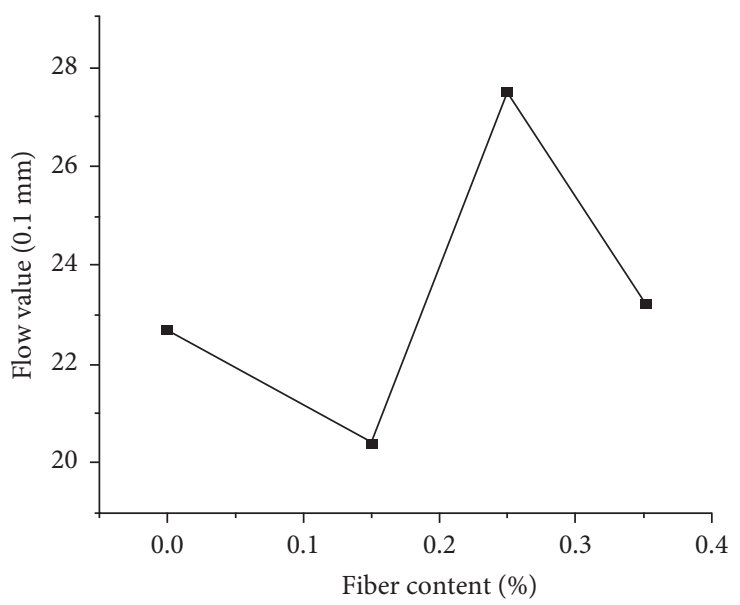

FIgURE 7: Relationship diagram of basalt fiber content and flow value.

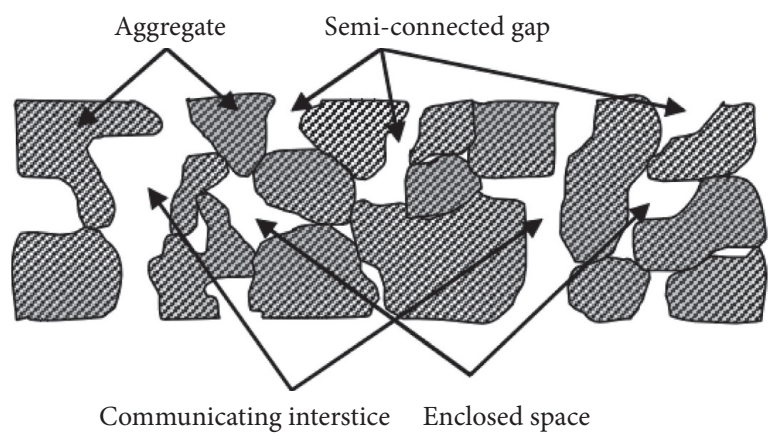

Figure 8: Gaps of drained asphalt mixture.

cracking of drainage asphalt pavement. SBS modified asphalt has better low temperature crack resistance. Therefore, SBS modified asphalt has the minimum stiffness modulus, the maximum creep rate, and the best low temperature crack resistance at the same temperature.

\subsection{Analysis on Road Performance}

4.3.1. High-Temperature Stability. The rutting test results are shown in Table 12. The deformation of basalt fiber SBS drainage asphalt mixture is the smallest, and the DS value is increased by $0.5 \%$ and $14.3 \%$, respectively, compared with TPS drainage asphalt mixture and nonfiber SBS drainage asphalt mixture. It shows that adding fiber under high temperature can improve the stability of the material, mainly reflected in two aspects: firstly, the reason of rutting is largely due to the decrease of asphalt viscosity under high temperature conditions, showing plastic characteristics. The 
TABLE 11: Experimental results of modified asphalt.

\begin{tabular}{lccc}
\hline Test metric & $7 \%$ SBS & $12 \%$ TPS & Specification requirement \\
\hline Penetration $\left(25^{\circ} \mathrm{C}, 0.1 \mathrm{~mm}\right)$ & 45.3 & 43.7 & $>40$ \\
Softening point $\left({ }^{\circ} \mathrm{C}\right)$ & 83.6 & 89.7 & $>80$ \\
Ductility $\left(5 \mathrm{~cm} \cdot \mathrm{min}^{-1}, 15^{\circ} \mathrm{C}\right)(\mathrm{cm})$ & 57.8 & 52.3 & $>50$ \\
Toughness $(\mathrm{N} \cdot \mathrm{m})$ & 21.7 & 24.6 & $>20$ \\
Tenacity $(\mathrm{N} \cdot \mathrm{m})$ & 16.3 & 18.8 & $>15$ \\
Dynamic viscosity at $60^{\circ} \mathrm{C}(\mathrm{Pa} \cdot \mathrm{s})$ & 20578 & 24984 & $>20000$ \\
\hline
\end{tabular}

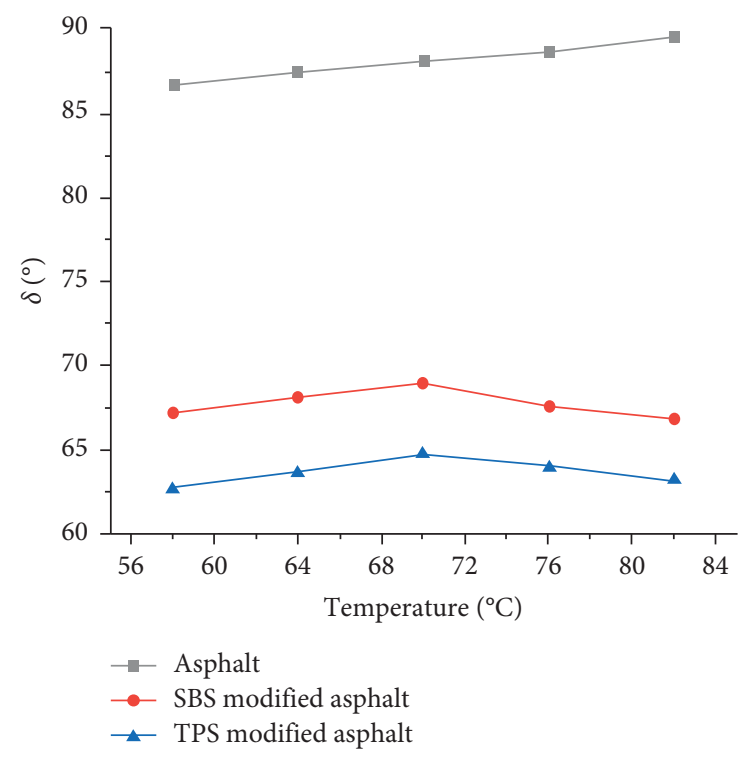

Figure 9: Temperature-phase angle diagram.

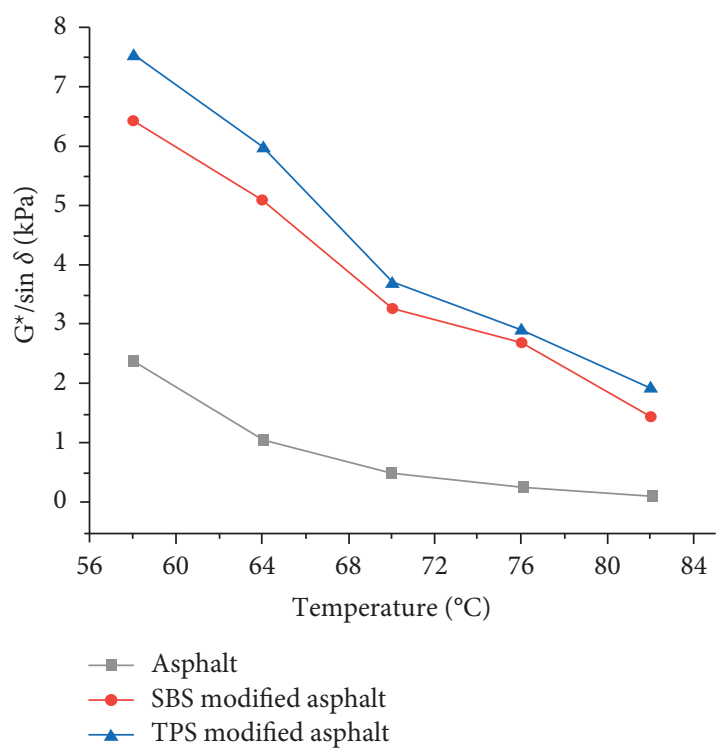

FIgURE 10: Temperature-rutting factor diagram.

addition of basalt fiber will adsorb more free asphalt, and the proportion of structural asphalt with strong adhesion will increase. Therefore, the adhesion of the mixture is enhanced, and the high temperature stability of the drainage asphalt mixture is improved; secondly, the fibers are evenly distributed in the mixture and overlap with each other to form a fiber

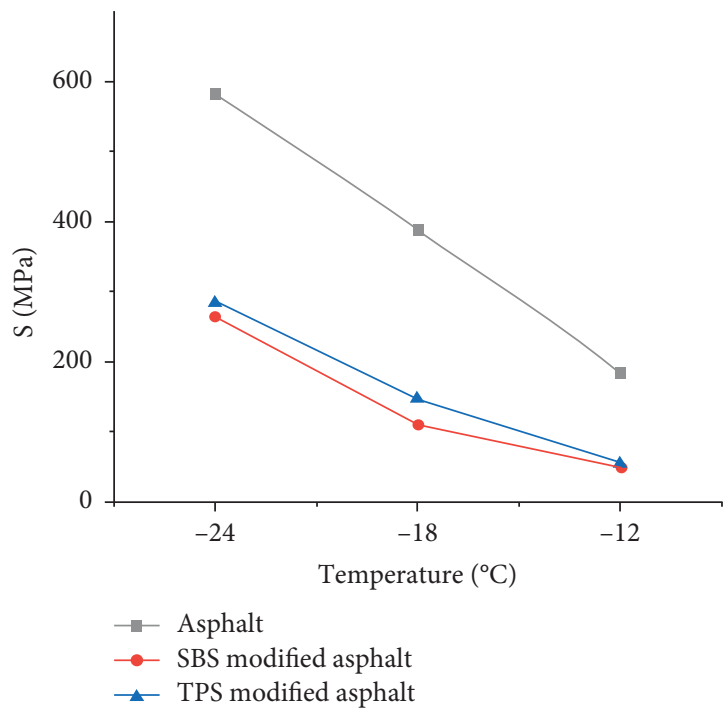

FIGURE 11: Stiffness modulus-temperature diagram.

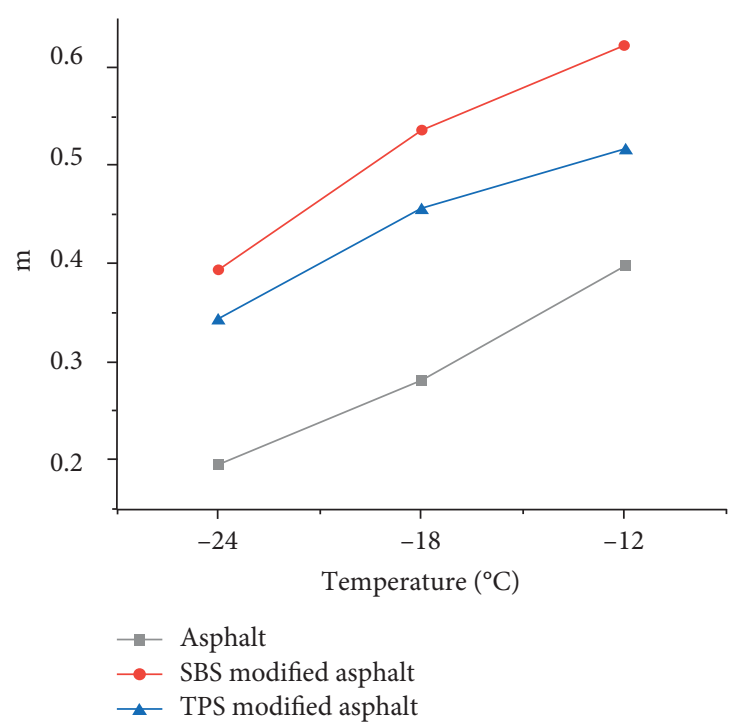

FIgURE 12: Relationship between creep rate and temperature.

skeleton network, which plays a role of reinforcement, restricting the free movement of aggregates and playing the role of hooping. Thus, the antideformation ability of the mixture is improved, so as to improve the high-temperature stability of the drainage asphalt mixture. Studies have shown that when the basalt content reaches $0.4 \%$, the high temperature stability of the $6 \mathrm{~mm}$ chopped basalt fiber mixture is the best, which is 1.8 times that of the ordinary asphalt mixture [31]. 
TABLE 12: Result of rutting test.

\begin{tabular}{lccc}
\hline Mixture type & 45 min deflection $(\mathrm{mm})$ & 60 min deflection $(\mathrm{mm})$ & ${\text { Dynamic stability }\left(\text { times } \cdot \mathrm{mm}^{-1}\right)}$ \\
\hline Fiber-free SBS & 1.77 & 1.99 & 2884 \\
Basalt fiber SBS & 1.55 & 1.74 & 3316 \\
TPS & 1.62 & 1.81 & 3298 \\
Technical standard & - & - & $\geq 3000$ \\
\hline
\end{tabular}

4.3.2. Water Stability. Relevant research shows that the water stability of $6 \mathrm{~mm}$ fiber asphalt mixture with $0.2 \%$ content is the best [31]. The water stability test results of three asphalt mixtures in this test are shown in Tables 13-15. Tables 13-15 show that the three performances of $0.25 \%$ basalt fiber SBS drainage asphalt mixture are the best. The residual stability, freeze-thaw splitting strength ratio, and immersion dispersion loss of $0.25 \%$ basalt fiber SBS drainage asphalt mixture are $2.7 \%, 5.6 \%$, and $4.9 \%$ higher than those of TPS drainage asphalt mixture, respectively, and $8.6 \%$, $8.5 \%$, and $8.5 \%$ higher than those of nonfiber SBS drainage asphalt mixture. The reason is that, similar to the high temperature stability of fiber reinforced drainage asphalt mixture, the addition of fiber increases the proportion of structural asphalt, the adhesion between asphalt and aggregate is enhanced, and the erosion of water is weakened. In addition, the network structure formed by fiber in the mixture increases the strength of the mixture. In addition, the raw material test shows that the moisture absorption of basalt fiber is poor, which can avoid its expansion at the interface and improve the water stability of drainage asphalt mixture.

4.3.3. Low Temperature Crack Resistance. Low temperature crack resistance test results are shown in Table 16; the analysis in Table 16 shows that the flexural stiffness modulus of basalt fiber SBS drainage asphalt mixture is the smallest, which is $5.7 \%$ and $10.2 \%$ lower than that of fiber-less SBS drainage asphalt mixture and TPS drainage asphalt mixture, respectively. This shows that the greater the energy required for material failure, the better the crack resistance at low temperature. The maximum flexural tensile strain of basalt fiber SBS drainage asphalt mixture is the largest, which is 9.5\% and $15.3 \%$ higher than that of nonfiber SBS drainage asphalt mixture and TPS drainage asphalt mixture, respectively. It shows that the higher the strain is, the better the resistance to low temperature deformation is. Cheng et al. studied the effect of basalt fiber content on the pavement performance of large-porosity asphalt mixture and found that basalt fiber could improve the splitting tensile strength of large-porosity asphalt mixture before and after freezing and thawing, indicating that basalt fiber had excellent lowtemperature crack resistance [32]. The low temperature crack resistance of basalt fiber SBS drainage asphalt mixture is the best, and TPS drainage asphalt mixture is the worst. The low temperature crack resistance of SBS modified asphalt is better than that of TPS modified asphalt. Basalt fiber SBS drainage asphalt mixture has the best low temperature crack resistance. Analyzing the reasons, the fibers overlap with each other in the mixture space to form a fiber grid.
Under low temperature conditions, it plays a role of tackifying, inhibits the flow of free asphalt, and enhances the bonding with aggregate. The elastic modulus of fiber is high, and the tensile strength is large, which can improve the overall performance of the mixture. In addition, fiber grid can spread the pavement load inside the mixture, reduce stress concentration, and prevent pavement cracking.

\subsection{Drainage Performance Analysis}

4.4.1. Connecting Void. The voids of drainage asphalt mixture include connected voids, semiconnected voids, and closed voids, as shown in Figure 8. The semiconnected voids can store water but cannot drain. The closed voids can neither store water nor drain. Only the connected voids can play the role of drainage. Therefore, it is extremely important to study the connected voids for drainage asphalt pavement.

The analysis of the test results is shown in Table 17. The void ratios of the three kinds of drainage asphalt mixtures are maintained at about $20 \%$, which meets the requirements of the initial void ratio of the drainage pavement. The connectivity porosity is above $15 \%$, so the three drainage asphalt mixtures all meet the requirements of drainage function of drainage pavement.

4.4.2. Analysis of Seepage Test. The seepage test results are shown in Table 18. The analysis of the test results shows that the seepage coefficient of basalt fiber drainage asphalt mixture is the smallest. The reason for the analysis is that the incorporation of fibers reduces the void ratio of the mixture. At the same time, the adsorption of fibers on asphalt increases the amount of asphalt and decreases the void ratio. However, the main factor affecting the void ratio is the gradation type, so the number of fibers and asphalt have little effect on the results, which also meets the specification requirements and has good drainage performance.

\subsection{Microscopic Mechanism Analysis}

\subsubsection{Scanning Electron Microscope Analysis}

(1) Analysis on Strengthening Effect of Bonding Interface between Fiber and Asphalt. The OGFC-13 asphalt mixture belongs to the skeleton void structure, and the interlocking force of mineral particles is not strong, mainly relying on the bonding effect of binder. In related studies, it is proposed that the combination mode between fiber and asphalt mixture is mainly mechanical connection and infiltration adsorption. Since the fiber surface is not smooth but has a certain roughness, convex and concave, the pits on the 
TABLE 13: Results of immersion Marshall test.

\begin{tabular}{lccc}
\hline Mixture type & Flood $0.5 \mathrm{~h}$ degree of stability $(\mathrm{kN})$ & Flood 48 Hd degree of stability $(\mathrm{kN})$ & Residual stability $(\%)$ \\
\hline Fiber-free SBS & 6.02 & 4.91 & 81.6 \\
$0.25 \%$ fiber SBS & 7.76 & 7.0 & 90.2 \\
TPS & 6.57 & 5.75 & 87.5 \\
Technical standard & - & - & $\geq 75$ \\
\hline
\end{tabular}

TABLE 14: Test results of freeze-thaw splitting.

\begin{tabular}{lccc}
\hline Mixture type & $\begin{array}{c}\text { Splitting strength of unfrozen specimen } \\
(\mathrm{MPa})\end{array}$ & $\begin{array}{c}\text { Splitting strength of freeze-thaw specimens } \\
(\mathrm{MPa})\end{array}$ & $\begin{array}{c}\text { Splitting } \\
\text { intensity ratio }(\%)\end{array}$ \\
\hline Fiber-free SBS & 0.60 & 0.47 & 78.2 \\
Basalt fiber SBS & 0.73 & 0.63 & 86.7 \\
TPS & 0.67 & 0.54 & 81.1 \\
Technical & - & - & $\geq 75$ \\
standard & & & \\
\hline
\end{tabular}

TABLE 15: Flight test results.

\begin{tabular}{lcr}
\hline Mixture type & Standard dispersion loss (\%) & Loss of immersion dispersion (\%) \\
\hline Fiber-free SBS & 11.1 & 20.0 \\
$0.25 \%$ fiber SBS & 6.7 & 11.5 \\
TPS & 9.8 & 16.4 \\
\hline
\end{tabular}

TABLE 16: Test results of low temperature bending.

\begin{tabular}{lccc}
\hline Type of asphalt mixture & Flexural tensile strength $(\mathrm{MPa})$ & Maximum bending strength $(\mu \varepsilon)$ & Bending stiffness modulus $(\%)$ \\
\hline Fiber-free SBS & 7.35 & 3197.3 & 2298.6 \\
Basalt fiber SBS & 7.59 & 3503.5 & 2166.4 \\
TPS & 7.33 & 3037.1 & 2413.7 \\
Technical standard & - & - & $\geq 2000$ \\
\hline
\end{tabular}

TABLE 17: Connected void fraction test results.

\begin{tabular}{lcc}
\hline Type of asphalt mixture & Percentage of void (\%) & Connecting porosity (\%) \\
\hline Fiber-free SBS & 20.1 & 17.34 \\
Basalt fiber SBS & 19.6 & 15.97 \\
TPS & 19.9 & 16.45 \\
\hline
\end{tabular}

TABle 18: Seepage test results.

\begin{tabular}{lccc}
\hline Type of asphalt mixture & The first timing $(\mathrm{s})$ & The second timing $(\mathrm{s})$ & ${\text { Water permeability coefficient }\left(\mathrm{mL} \cdot \mathrm{min}^{-1}\right)}^{-1.4}$ \\
\hline Fiber-free SBS & 1.4 & 7.2 & 4137.9 \\
Basalt fiber SBS & 1.2 & 7.5 & 3809.5 \\
TPS & $1.4 \mathrm{y}$ & 7.4 & 4000.0 \\
Specification requirement & - & - & $>3600$ \\
\hline
\end{tabular}

surface of asphalt and fiber form a more compact combination [33]. It can be seen from Figure 13 that the mineral aggregate in the nonfiber SBS drainage asphalt mixture is not closely bonded to the asphalt, and there are a large number of voids. Therefore, with the increase of temperature and the erosion of water, the mineral aggregate is easy to peel off from the asphalt surface, resulting in rutting, pits, and other damage. The fiber diameter is small, and the mixed mixture has a huge specific surface area. The fiber surface is adsorbed by a large amount of asphalt, and the root is closely bonded with the asphalt mixture. This shows that the infiltration between fiber and asphalt liquid is great, and the bonding degree of the interface between the two is significantly greater than that between the mineral aggregate of nonfiber asphalt mixture and asphalt.

Figure 14 shows that fiber and mixture are combined by mechanical connection and infiltration adsorption. Basalt fiber has a certain roughness and unevenness. Asphalt phase extends to the pits on the surface of fiber phase, forming a closer combination. When asphalt phase 


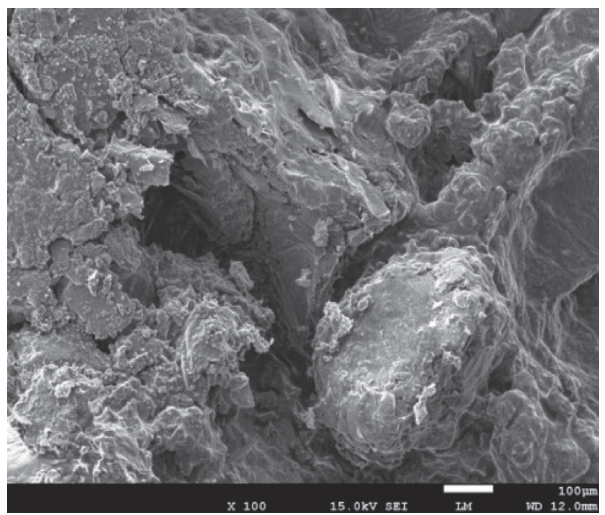

FIGURE 13: Bonding interface between asphalt and ore in fiber free asphalt mixture.

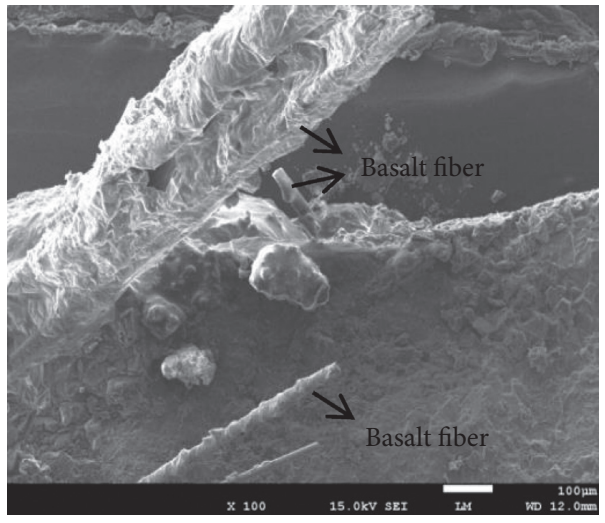

FIgURE 14: The bonding interface between basalt fibers and bitumen.

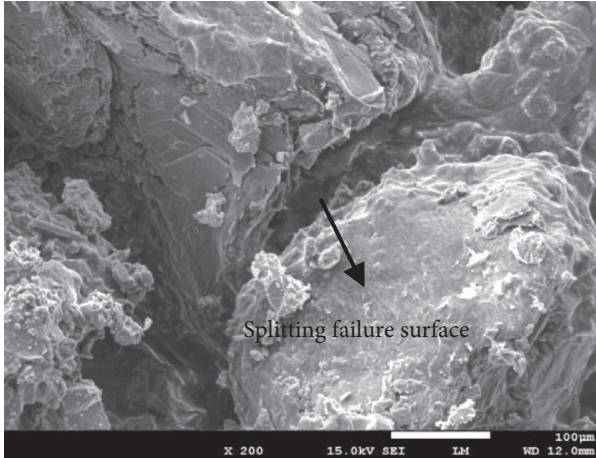

(a)

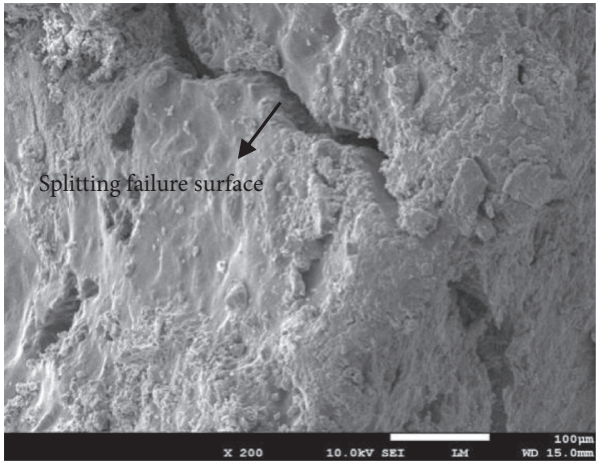

(b)

FIgURE 15: Breakdown of asphalt mixture without fiber drainage.

contacts with fiber, it is surface contact, resulting in the effect equivalent to mechanical anchor sum. It has a large bite force and improves the high temperature stability of drainage asphalt mixture by improving the bond strength. Transition layer refers to the structural asphalt layer, and the transition layer between free asphalt and fiber can connect two phases. There are two forms of asphalt in the mixture. One is the constrained structural asphalt, and the other is the free asphalt without contact with the entity. The constrained structural asphalt has stronger bonding force. The adsorption of fiber makes free asphalt transform into transition layer structure asphalt at the contact point of the two. The fiber with large specific surface area will form a large number of transition layers in the mixture, and the proportion of structural asphalt with higher cohesive force increases. Therefore, the addition of fiber can improve the high and low temperature stability and water stability of drainage asphalt mixture. The incorporation of basalt fiber changes the effect of each phase interface of drainage asphalt 


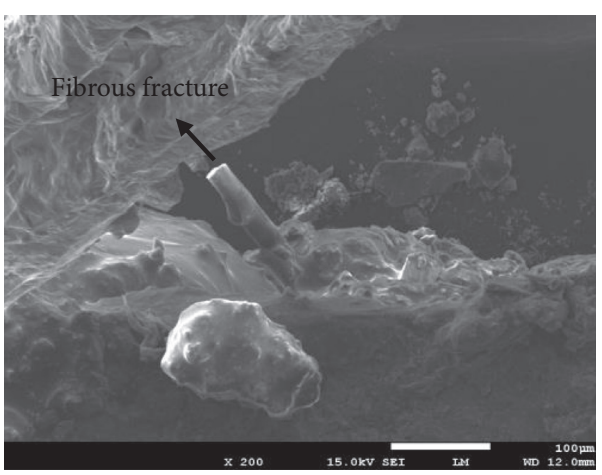

(a)

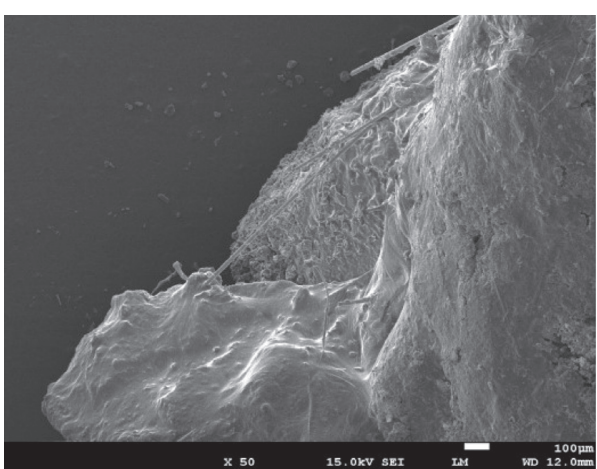

(b)

FIgURE 16: Fracture of basalt fiber drainage asphalt mixture.

mixture and improves the road performance of drainage asphalt mixture.

(2) Effect of Fiber on Reinforcement and Crack Resistance of Drainage Asphalt Mixture. It can be seen from Figure 15 that the splitting failure surface of fiber-free SBS drainage asphalt mixture has many cracks and different stripping levels. The mineral material is in a state of separation, and the connection is extremely weak. The microscopic picture of drainage asphalt mixture with basalt fiber is shown in Figure 16.

The main failure mode of asphalt mixture in use is shear failure, which starts from the internal voids of asphalt mixture and spreads along the original voids, especially the interface between asphalt and mineral [33]. The basalt overlaps vertically and horizontally in the mixture to form a spatial network structure. When the asphalt pavement is subjected to load, the spatial network structure can transfer stress and reduce stress concentration, which is similar to the role of reinforcement in reinforced concrete. It can also inhibit the free movement of particles, play a 'hoop' role in the mixture, and improve the overall mechanical properties of drainage asphalt pavement. It can be seen from the photographs of the fiber fracture that the fiber is interspersed in the asphalt mixture, and the root is absorbed by the asphalt and buried in the internal of the asphalt mixture, indicating that the basalt fiber and the asphalt mixture have strong adhesion and crack resistance.

\section{Conclusion}

(1) Compared with TPS drainage asphalt mixture and nonfiber SBS drainage asphalt mixture, basalt fiber SBS drainage asphalt mixture can better improve the high temperature stability of drainage asphalt mixture. $0.25 \%$ basalt fiber SBS drainage asphalt mixture has the best three properties, indicating that its water stability is the best; the maximum bending strain of basalt fiber SBS drainage asphalt mixture is the largest, which shows that its resistance to low temperature deformation is better than the other two kinds of drainage asphalt mixture.

(2) The optimum asphalt content of BS drainage asphalt mixture with basalt fiber content of $0 \%, 0.15 \%$, $0.25 \%$, and $0.35 \%$ is $4.9 \%, 5.05 \%, 5.15 \%$, and $5.2 \%$, respectively. When the content of basalt fiber is $0.25 \%$, the stability reaches the peak, and the leakage loss rate and the dispersion loss rate reach the minimum. Therefore, $0.25 \%$ is selected as the optimal content of basalt fiber.

(3) The high temperature performance, water stability, low temperature performance, and drainage performance of $0.25 \%$ basalt fiber SBS drainage asphalt mixture can meet the specification requirements, and the performance is better. Compared with no fiber SBS drainage asphalt mixture and TPS drainage asphalt mixture, the dynamic stability, residual stability, and freezethaw splitting strength are improved. Dip loss and bending stiffness modulus decrease. The connectivity porosity of basalt fiber SBS drainage asphalt Marshall specimen is $15.97 \%$, and the permeability coefficient is $3809.5 \mathrm{~mL} / \mathrm{min}$, which meets the requirements of the specification. Therefore, SBS drainage asphalt mixture with basalt fiber has good performance and can be applied in drainage pavement.

(4) The root of basalt fiber mixed with asphalt mixture is closely bonded with the mixture, and the bonding degree of the interface between basalt fiber and asphalt mixture is significantly greater than that of the mineral aggregate and asphalt mixture without basalt fiber, which has a large bite force and improves the bonding strength, indicating that the infiltration effect between basalt fiber and asphalt is good; and the bonding interface bonding degree of the two is significantly greater than that of the fiber-free asphalt mixture mineral and asphalt joint. The formation of network structure in the mixture inhibits the further diffusion of cracks and improves the high and low temperature performance and water stability of drainage asphalt mixture.

\section{Data Availability}

Some or all data, models, or code that support the findings of this study are available from the corresponding author upon reasonable request. 


\section{Conflicts of Interest}

The authors do not have any conflicts of interest with other entities or researchers.

\section{Authors' Contributions}

Writing and original draft preparation are done by Li, Z. X., and $\mathrm{M}$. H. Zhang.; writing and review and editing are done by Guo, T. T., Y. Z. Chen, and Q. Y. Xu.; investigation is done by Wang, J., and L. H. Jin.; discussion is done by Y Guo, T. T., Y. Z. Chen, and Q. Y. Xu. All authors have read and agreed to the published version of the manuscript.

\section{Acknowledgments}

This work was supported by Key R\&D and Promotion of Special Scientific and Technological Research Projects of Henan Province: [Grant Number 182102210061, 212102310089]; Key Scientific Research Projects of Colleges and Universities in Henan Province in 2021: Study on pavement performance of cotton straw cellulose modified asphalt [Grant Number 21A580004].

\section{References}

[1] M. C. Ji and X. Bai, "Construction of the sponge city regulatory detailed planning index system based on the SWMM model," Environmental Technology \& Innovation.vol. 23, no. 5, 2021.

[2] W. Chen, M. L. Zheng, Q. Gao, M. Yue, G. Q. Ji, and C. X. Deng, "Attenuation law of permeable pavement in sponge city," Journal of Chang'an University (Natural Science Edition), vol. 41, no. 3, pp. 12-21, 2021.

[3] W. T. Huang, X. Liu, S. W. Zhang, Y. Zheng, Q. L. Ding, and B. Tong, "Performance-guided design of permeable asphalt concrete with modified asphalt binder using crumb rubber and SBS modifier for sponge cities," Materials, vol. 14, no. 5, 2021.

[4] J. P. Wang, X. D. Lian, Y. J. Fan, and L. Z. Cai, "Long-term performance investigation and evaluation of porous asphalt pavement for guangxi nanyou highway," Journal of China \& Foreign Highway, vol. 40, no. 3, pp. 80-84, 2020.

[5] Z. C. Li, B. Yuan, J. P. Zhang, and W. L. Liu, "“Urban rainfall characteristics and permeable pavement structure optimization for sponge road in North China." Water science and technology," A Journal of the International Association on Water Pollution Research, vol. 83, no. 8, 2021.

[6] Y. F. Yuan, X. J. Bai, L. Y. Wang, and M. Zhang, "Experimental study on mixture of asphalt pavement under doublelayer drainage and noise reduction," Journal of China \& Foreign Highway, vol. 34, no. 3, pp. 275-279, 2014.

[7] M. J. Hu, G. Q. Sun, D. Q. Sun, T. Lu, J. M. Ma, and Y. Deng, "Accelerated weathering simulation on rheological properties and chemical structure of high viscosity modified asphalt: a temperature acceleration effect analysis," Construction and Building Metrials, vol. 268, 2021.

[8] S. Q. Yang, L. Lu, S. X. Su, and S. Suang, "Study on compatibility test and index performance of polymer high viscosity modified asphalt," Highway Engineer, pp. 1-10, 2021.

[9] B. Xu, M. L. Li, S. H. Liu, J. Fang, R. Ding, and D. W. Cao, "Performance analysis of different type preventive maintenance materials for porous asphalt based on high viscosity modified asphalt," Construction and Building Materials, vol. 191, 2018.

[10] J. Han, X. F. Yu, D. H. Zhou, X. Y. Hu, and G. J. Zhu, "Preparation process and performance of basalt fiber reinforced high viscosity asphalt mixture," Journal of China \& Foreign Highway, vol. 35, no. 2, pp. 217-220, 2015.

[11] Z. Gao, P. Zhang, K. Wang, and J. Guo, "Bonding behavior of concrete matrix and alkali-activated mortar incorporating nano-SiO2 and polyvinyl alcohol fiber: theoretical analysis and prediction model," Ceramics International, vol. 47, no. 22, pp. 31638-31649, 2021.

[12] M. J. Hu, D. Q. Sun, Y. Zhang et al., "Evaluation of weathering aging on resistance of high viscosity modified asphalt to permanent deformation and fatigue damage," Construction and Building Materials, vol. 264, 2020.

[13] L. H. Li, H. Geng, Y. N. Sun, and N. Q. Meng, "Viscosity evaluating indicators and criteria of high-viscosity modified asphalt," Journal of Tongji University, vol. 38, no. 8, pp. 1157-1159, 2010.

[14] E. Arambula, S. Silvia, and E. Masad, "Experimental measurement and numerical simulation of water vapor diffusion through asphalt pavement materials," Journal of Materials in Civil Engineering, vol. 22, no. 6, 2010.

[15] A. H. S. Maria, C. Silvia, A. M. Edith, and E. M. Amy, "Design,Performance and maintenance of permeable friction courses in the United States:state of the art," Construction and Building Materials, vol. 111, no. 5, pp. 358-367, 2016.

[16] S. F. Cui, "Study on performance of the porous asphalt mixture with wood fibers," Journal of China \& Foreign Highway, vol. 39, no. 2, pp. 223-226, 2019.

[17] P. Zhang, Z. Gao, J. Wang, and K. Wang, "Numerical modeling of rebar-matrix bond behaviors of nano-SiO2 and PVA fiber reinforced geopolymer composites," Ceramics International, vol. 47, no. 8, pp. 11727-11737, 2021.

[18] K. Zhang, Y. L. Liu, N. Somayeh, H. Liu, and E. Karl, "Englund Karl. Performance evaluation of porous asphalt mixture enhanced with high dosages of cured carbon fiber composite materials," Construction and Building Materials, vol. 274, 2021.

[19] H. P. Li, F. M. Wang, and C. Chen, "Influence of basalt fiber on asphalt mixture performance," Journal of China \& Foreign Highway, vol. 36, no. 4, pp. 323-327, 2016.

[20] E. Quan, Y. S. Cao, H. K. Xu, and M. Bonding, "Bonding performance and evaluation of basalt fiber asphalt macadam seal," Advances in Civil Engineering, vol. 2020, Article ID 889570, 10 pages, 2020.

[21] X. Y. Zhang and J. X. Liu, "Jiaxing. Viscoelastic creep properties and mesostructure modeling of basalt fiber-reinforced asphalt concrete," Construction and Building Materials, vol. $259,2020$.

[22] H. Zhang, P. W. Hao, T. Q. Ling, X. W. Wang, and L. He, "Analysis of microscopic structure of composite fiber asphalt mixture subjected to repeated loading under high temperature," Materials Reports, vol. 32, no. 6, pp. 987-994, 2018.

[23] S. F. Chen, H. B. Dou, M. L. Xing, R. He, and Z. Z. Liu, "Study on high temperature rheological properties of TPS high viscosity modified asphalt mortar," Journal of Xi'an University of Architecture and Technology, vol. 46, no. 3, pp. 380-384, 2014.

[24] P. Zhang, K. Wang, J. Wang, J. Guo, S. Hu, and Y. Ling, "Mechanical properties and prediction of fracture parameters of geopolymer/alkali-activated mortar modified with PVA fiber and nano-SiO2," Ceramics International, vol. 46, no. 12, pp. 20027-20037, 2020. 
[25] X. Li, "Performance of CR/TPS composite modified asphalt and porous asphalt mixture," New Building Materials, vol. 47, no. 7, pp. 95-98+103, 2020.

[26] Z. G. Zhou, G. H. Chen, H. B. Zhang, and Y. Y. Ling, "Study on the preparation and properties of modified asphalt by rubber powder/SBS and high viscosity modifier composite," Materials Reports, vol. 35, no. 6, pp. 6093-6099, 2021.

[27] C. Wang, Q. Chen, T. Guo, and Q. Li, "Environmental effects and enhancement mechanism of graphene/tourmaline composites," Journal of Cleaner Production, vol. 262, no. 2, Article ID 121313, 2020.

[28] L. Song, Z. H. Wang, C. Shu, and L. Q. Liu, "Research progress and performance evaluation of SBS/CR modified asphalt," China Journal of Highway and Transport, vol. 34, pp. 1-24, 2021.

[29] D. Kaya, A. Topal, J. Gupta, and T. McNally, "Derya Kaya, Ali Topal, Jaipal Gupta, Tony McNally. Aging effects on the composition and thermal properties of styrene-butadienestyrene (SBS) modified bitumen," Construction and Building Materials, vol. 235, 2020.

[30] G. Peng, F. L. Xie, J. W. Meng, X. C. Meng, and Z. He, "Research on performance of modifiedn wood fiber asphalt and SMA-13 asphalt mixture," Applied Chemical Industry, vol. 49, no. 07, pp. 1634-1637, 2020.

[31] H. B. Huang, J. Chen, and L. Yang, "Experimental study on fatigue properties of basalt fiber asphalt mixture," Subgrade Engineering, no. 4, pp. 89-93, 2021.

[32] Z. Q. Cheng, L. J. Hou, Y. X. Zhou, and X. C. Zhao, "Effect of basalt fiber content on the road performance of large-void asphalt mixture," Journal of Materials Science and Engineering, vol. 39, no. 5, pp. 736-744, 2021.

[33] Z. X. Li, Y. Z. Chen, J. B. Zhou et al., "Analysis of road performance and fiber mechanism for corn stalk fiber asphalt mixture," China Journal of Highway and Transport, vol. 32, no. 2, pp. 47-58, 2019. 